Revista de Psicología Vol. 34 (2), 2016 (ISSN 0254-9247)

\title{
Estetización del selfen redes sociales: contradicciones humanas y producción subjetiva contemporánea
}

\author{
Gabriel Artur Marra e Rosa ${ }^{1}$, Benedito Rodrigues dos Santos ${ }^{2}$, \\ Márcia Stengel ${ }^{3}$ y Marta Helena de Freitas ${ }^{4}$ \\ Universidad del Salvador, Argentina ${ }^{1}$, Universidade Católica de Brasilia ${ }^{2,4}$ \\ y Pontifícia Universidade Católica de Minas Gerais, Brasil ${ }^{3}$
}

El presente artículo analiza los sentidos atribuidos por los usuarios de las redes sociales de internet al fenómeno de la estetización del self, producto del proceso de negociación de identidades entre sus participantes. El objetivo es unirse a los esfuerzos por la superación de la dicotomía establecida entre concepciones dispares de las identidades en el ambiente de redes sociales y aportar una concepción que favorezca la operacionalización de esta categoría de estudios. La metodología se constituyó en una investigación cualitativa con base en entrevistas semiestructuradas con 16 usuarios del Facebook de ambos sexos, de diferentes edades, etnias y niveles socioeconómicos, todos residentes en Brasilia-DF. Como resultado, constatamos un proceso dialéctico de producción subjetiva entre los usuarios de las redes sociales. Palabras clave: redes sociales; subjetividad; estetización del self; negociación de identidades.

1 Doctor en Psicología y profesor titular de la Facultad de Psicología y Psicopedagogía de la Universidad del Salvador. Dirección postal: Universidad del Salvador. Champagnat 1599, Pilar, Buenos Aires-BA, Argentina. Contacto: gabriel_marra@hotmail.com

2 Doctor en Antropología, profesor titular del Programa de Posgrado Stricto Sensu en Psicología de la Universidad Católica de Brasilia. Dirección postal: Universidade Católica de Brasília, PróReitoria de Pós-Graduação e Pesquisa, Mestrado Em Psicologia. SGAN 916, Módulo B, W5 Norte, Asa Norte, 70790160 - Brasília, DF Brasil. Contacto: benedito.santos.br@gmail.com

3 Doctora en Ciencias Sociales, profesora titular de los Programas de Grado y Posgrado de la Pontificia Universidad Católica de Minas Gerais. Dirección postal: Pontifícia Universidade Católica de Minas Gerais, Departamento de Psicologia. Avenida Itaú 525, Dom Cabral, 30535-012, Belo Horizonte, MG - Brasil. Contacto: marciastengel@gmail.com

4 Doctora en Psicología, profesora titular del Programa de Posgrado Stricto Sensu en Psicología de la Universidad Católica de Brasilia. Dirección postal: Universidade Católica de Brasília, PróReitoria de Pós-Graduação e Pesquisa, Mestrado Em Psicologia. SGAN 916, Módulo B, W5 Norte, Asa Norte, 70790160 - Brasília, DF - Brasil. Contacto: mhelenadefreitas@gmail.com 


\section{Aestheticization of the self in social networks: human contradictions and contempo- rary subjective production}

This paper analyzes the meanings attributed by social network users to the aestheticization of the self-phenomenon, product of the identities negotiation process among its participants. The objective is to join efforts to overcome the dichotomy established between disparate identity conceptions in the social network environment, and provide a concept that favors the operationalization of this category of studies. The study employed a qualitative methodology, conducting 16 semi-structured interviews with male and female Facebook users of diverse ages, ethnicities and socioeconomic levels; all residents in Brasilia-DF. A dialectical subjective production process among social network users was verified.

Keywords: Social network; subjectivity; aestheticization of the self; identities negotiation.

\section{Estetizaçáo do self nas redes sociais: contradiçóes humanas e produçáo subjetiva con- temporânea}

O presente artigo analisa os significados atribuídos pelos usuários de redes sociais de Internet ao fenômeno da estetizaçáo do self, produto do processo de negociação de identidades entre seus participantes. O objetivo é unir-se aos esforços pela superação da dicotomia estabelecida entre concepçóes díspares de identidades no ambiente de redes sociais e proporcionar uma concepção que favoreça a operacionalização desta categoria de estudos. A metodologia constituiu-se em uma pesquisa qualitativa baseada em entrevistas semi-estruturadas com 16 usuários de Facebook de ambos sexos, de diferentes idades, etnias e níveis socioeconômicos, todos os participantes são residentes de Brasília-DF. Como resultado, encontramos um processo dialético de produção subjetiva entre os usuários das redes sociais.

Palavras chave: redes sociais; subjetividade; estetização do self; negociação de identidades. 
Los sitios de redes sociales han revelado una modalidad enteramente nueva de presentación y de interacción. Este modus ha sido considerado, por los investigadores, un campo propenso para analizar los fenómenos relacionados a la identidad y a la personalidad (Mehdizadeh, 2010; Rosa \& Santos 2013). En lo que se refiere, específicamente, a la identidad, las formas derivadas de esta modalidad de presentación y de interacción entre los usuarios conectados por las redes ha sido el foco de las investigaciones que buscan desvendar la lógica subyacente de este fenómeno y sus posibles implicaciones (Zarghooni, 2007).

La literatura especializada en el tema de la identidad en las redes sociales coloca en evidencia una diversidad conceptual que denota las diferentes formas de observar a este fenómeno. En este contexto, bajo el consenso de que cada usuario se presenta a sí mismo en las redes (self-presentation), sobrevienen dos concepciones preponderantes. La primera argumenta que existe un proceso de construcción de identidad (Zhao, Grasmuck \& Martin, 2008; Mehdizadeh, 2010; Fonseca, 2010). La segunda propone que ocurre un gerenciamiento de las identidades de los participantes (Dimicco \& Millen, 2007; Strano, 2008; Magalhães \& Paiva, 2009). La contraposición entre esas nociones teórico-conceptuales genera dificultades a la comprensión del modus operandi de esta modalidad de presentación de sí mismo (self), de sus desdoblamientos en el ambiente de las redes sociales y de sus posibles repercusiones en la subjetividad de los usuarios.

En una primera mirada, nuestra concepción es la de que cada participante selecciona lo que va a exponer y ocultar respecto de sí mismo. Por lo tanto, cada persona tiende a exponer los aspectos considerados positivos en relación con su forma de ser, pensar y sentir. Cada usuario, con base en la prerrogativa como quiero que me vean, tiende a exponer rasgos y características de su identidad que considera positivos, utilizando los recursos y dispositivos presentes en las redes para estetizar 
de esta manera su autopresentación. Consecuentemente, los aspectos negativos tienden a ser ocultados o disimulados cuando se trata de interactuar y de participar en el ambiente online. De este modo, no se estaría construyendo una nueva identidad, pero, sí, negociando rasgos identificatorios según las personas envueltas en esas negociaciones y los intereses contrapuestos en cada circunstancia (Rosa \& Santos, 2013).

No obstante la existencia de algunas similitudes entre las concepciones mencionadas, la dificultad de comprensión del fenómeno de estetización del self en ambientes de redes sociales se vuelve evidente cuando, por ejemplo, al intentar distinguir si el resultado de este proceso denominado construcción o gerenciamiento es la recreación de las identidades en las redes sociales (Yurchisin, Watchravesringkan \& McCabe, 2005) o la idealización de los aspectos considerados positivos (Siibak, 2007). En otras palabras, afirmar que las identidades expuestas por los usuarios corresponden a sus propias identidades o, al contrario, que son identidades falsas o construidas por ellos se torna una misión arriesgada. Considerando que, en general, las redes sociales son diferentes de otros ambientes de la web en los cuales se utiliza el anonimato (Zhao, Grasmuck \& Martin, 2008), se resalta que se trata de un ambiente en el cual hay prevalencia de datos considerados verídicos. De esta manera, incurre el cuestionamiento sobre hasta qué punto esos datos, en lo que se refiere a las identidades de los usuarios, pueden ser considerados una construcción, un gerenciamiento, una idealización o una supuesta recreación de las identidades. En efecto, sobreviene la necesidad de elucidar mejor las peculiaridades de ese fenómeno para destrabar el debate y para propiciar una comprensión aún más elaborada de lo que sucede con base en esta manera de presentarse, interactuar y, por consiguiente, de ser y de estar en las redes sociales de internet.

Complementando, en una segunda mirada, se muestra útil el rescate etimológico del término persona y sus relaciones con la identidad. En el teatro griego, el término persona se refería a la "máscara que colocada sobre la cara y delante de los ojos, oculta el rostro, la face" (Teixeira, 1992, p. 98). Esta transformación histórica del sentido inicial puede parecer extrańa y bastante paradójica: ¡cómo se puede comprender que 
solo la máscara, aspecto superficial y falso de la identidad, pueda significar el aspecto más genuino y característico del individuo? Pero, como bien acentúa Leite (1967), esto puede ser psicológicamente comprensible cuando se considera al aspecto dialéctico, ambiguo polivalente de la relación entre el actor y la máscara, entendida como objeto escénico. Ocurre que el sentido teatral, intrínseco a la palabra persona/máscara — a saber, el de ocultamiento de la verdadera identidad del actor- no ha desaparecido; pero, a la vez, también intrínseco a este entendimiento consta el de que "el aspecto que el individuo decide revelar no es menos característico de su persona que los otros, hipotéticamente guardados" (Leite, 1967, p. 5). En otras palabras, muchas veces el empleo de un "disfraz, de otro 'personaje", es justamente la oportunidad de revelarse, como ilustra la película "The Mask", de Chuck Russell, en la performance del personaje representado por Jim Carrey.

Por otro lado, el aspecto exterior de aquello que es mostrado/ representado, aunque "falso" o "incompleto", tiene efecto dinámico significativo. En el caso de las redes sociales, se puede suponer que, al ser identificado justamente a través del aspecto exterior, mostrado en aquella especie de "recreación" de identidad, supuestamente estetizada, sus participantes pueden identificarse por medio de ello. Esta última perspectiva está presente, por ejemplo, en el pensamiento de Ichheister, cuyas ideas fueron clave para el intelectual austríaco Goffman (Velho, 2008), y queda ilustrada en una citación literal reproducida por Leite (1967, p. 5): "los otros son nuestros espejos". Por consiguiente, se infiere que por medio de los otros y de sus reacciones a lo que les es explícitamente mostrado o no, es que una persona puede llegar a ser lo que de hecho es.

En este contexto, con la intención de optimizar el debate sobre esta temática, un camino que se nos presenta como promisorio es el del análisis de las características y de las repercusiones de esta modalidad de autopresentación y de interacción en la subjetividad de los participantes de estas redes. Y para reforzar la importancia de esta inquietud, resaltamos que consideramos la existencia de congruencias entre este fenómeno de la estetización del selfy lo que el cine había creado como 
un sueño inaccesible e intocable, que es el de ser el actor y a la vez el director del propio film (Lipovetsky \& Serroy, 2007/2009). Partiendo de esta comparación, la frase-síntesis de la cultura patrimonialista y de mando brasileña "Sabe usted con quién está hablando" (Você sabe com quem está falando?) (DaMatta, 1986), podría, aquí, ser repensada e un sentido aún más cuestionador: ¿Esta modalidad de mostrarse en las redes repercute en la forma de ser de las personas?

Entre los esfuerzos realizados para desarrollar esa línea de investigación, destacase la concepción de que hay un proceso de negociación de identidades (Rosa \& Santos 2013, 2014a) que culmina con la perspectiva de la existencia de un fenómeno de estetización del self en las redes sociales. Esta concepción se fundamenta en la perspectiva de que ocurre una selección de rasgos y de características propias de las identidades de los usuarios que son exhibidos u ocultados por medio de la exposición de gustos y de preferencias culturales que figuran en los perfiles, en lo que se postea y en los comentarios realizados en las redes. Este punto de vista propone que, a partir de este habitus (Bourdieu, 1977) comunicacional e interaccional, los usuarios utilizan tácticas que tienen como objetivo utilizar los recursos y dispositivos ofrecidos por las redes para representarse a sí mismos (Goffman, 1975/2009) en este ambiente a través de textos, imágenes y videos. Esa representación, por consiguiente, tiende a ser efectuada de un modo en que no se expongan características consideradas negativas que puedan demostrar vulnerabilidad, baja autoestima y dificultades personales (Rosa \& Santos, 2013; 2014b).

Siguiendo por esta línea de raciocinio, el llamado fenómeno de la estetización del self parte de la suposición de que sucede un embelesamiento creativo de ese selfque, supuestamente, puede acarrear algún tipo de repercusión en la subjetividad de los participantes. Tal concepción se aproxima de la noción de gerenciamiento, sin embargo, se aleja de esta por enfatizar que hay un proceso dialéctico en el cual los intereses, las circunstancias, el contexto y las personas relacionadas influencian, de forma constante, la manera como cada participante se presenta e interactúa en las redes. Es decir, yendo más allá de una gestión efectuada 
de manera unidireccional por el usuario, la concepción de que hay un proceso de negociación de identidades sugiere que la forma como la persona se representa en las redes es directamente influenciada por las interacciones que acontecen en la continuidad de lo que se da dentro y fuera de estas redes. Por eso, incluye a la participación de los demás contactos y del contexto en esta forma de representarse y presupone que no hay idealización o recreación de identidades, pero sí un fenómeno de estetización del self que se manifiesta en las transacciones que las personas realizan para con ellas mismas y para con los otros con los cuales ellas interactúan cotidianamente.

Con base en esas consideraciones teóricas, entrevistamos usuarios de la mayor red social de todos los tiempos - Facebook - y analizamos sus relatos con el objetivo de explorar cuales son los principales sentidos que los participantes atribuyen a aquello que se concibe como estetización del self en las redes sociales. A lo largo de este proceso de análisis, evidenciamos que todos los usuarios entrevistados concuerdan con la existencia de este fenómeno y que ellos le atribuyen sentidos contradictorios al mismo. Las referidas contradicciones fueran agrupadas en los principales núcleos de sentido encontrados. Los nombres utilizados para representar a los participantes son ficticios y las narrativas más expresivas fueron elegidas para demostrar cómo los participantes comprenden a esas contradicciones que, en nuestra opinión, pueden ser las propulsoras de este fenómeno.

\section{Método}

Los datos empíricos fueran obtenidos por medio de entrevistas semiestructuradas (Groeben, 1990) realizadas a 16 usuarios de Facebook, los cuales fueran seleccionados y subdivididos en categorías con base en los siguientes criterios de inclusión: sexo, etnia/color de piel, nivel socioeconómico y edad. El sitio de redes sociales Facebook fue elegido como base empírica debido a su representatividad con relación a las demás redes sociales de internet. 
Teniendo como referencia a la metodología cualitativa de investigación, esa división se dio con la finalidad de comparar los relatos concedidos por ocho pares de usuarios de Facebook, compuestos por hombres y mujeres que se autodeclararon de color de etnia/color de piel negra o blanca, de niveles socioeconómicos alto o bajo y que nacieron antes o después de la década de 1990, época en la cual surgió el site que fue considerado la primera red social de internet, el SixDegrees (Lemos \& Lévy, 2010). La categorización de los niveles socioeconómicos se realizó por medio de la utilización del Critério Brasil de Classificação Económica (Abep, 2012) siendo las clases A1, A2, B1 y B2 consideradas el nivel socioeconómico alto, y las clases $\mathrm{C} 1, \mathrm{C} 2$ y E el nivel socioeconómico bajo.

Los principales temas abordados en las entrevistas fueron: cómo ha sido la experiencia de cada usuario en las redes; la opinión sobre la existencia o no del fenómeno de la estetización del self; cuáles son los posibles efectos de las redes en la forma en que los usuarios ven el mundo, a sí mismos y a las otras personas; las posibles transformaciones generadas por las redes sociales en la vida de uno. Esos fueron los principales tópicos transformados en categorías de análisis que, con base en la técnica de la Descripción Densa o Thick Description (Geertz, 1988/2008), posibilitaron la interpretación interdisciplinaria de los sentidos y significados atribuidos por los usuarios al referido fenómeno de la estetización del self.

\section{Resultados}

En el trascurso de las entrevistas, todos los participantes alegaron estar de acuerdo con la tesis de la estetización del self en lo que concierne a la exposición de rasgos y de características de identidad considerados positivos. No hubo discrepancia con relación a los segmentos de análisis. No obstante, percibimos algunas divergencias respecto a lo que piensan sobre el fenómeno en lo que se refiere a sus posibles causas, sus desdoblamientos y consecuencias. Asimismo, en un 
primer plan de análisis, las principales opiniones sobre este fenómeno fueron las siguientes: hay miedo de ser criticado; hay miedo de exponer a las demás personas; es una forma falsa de exponerse en las redes. Con relación al miedo de ser criticado, la entrevistada Verónica expresó, con vehemencia, su opinión:

Seguro, es verdad. Nadie va a postear una foto con una cara llena de granitos, fea, cuando acaba de levantarse. Las personas tienen miedo de ser criticadas. Yo mismo pongo una foto y si alguien va y me critica... nadie acepta ser criticado. Entonces, yo creo que eso es verdad.

Con una opinión semejante, la entrevistada Mariana destacó el envolvimiento emocional de otras personas:

Es verdad porque yo, por ejemplo, no posteo cualquier cosa. Si yo tengo alguna cosa negativa, yo no posteo porque sé que envuelve mucha gente; mucha gente está viendo, puede perjudicar en el trabajo, puede molestar. Aün que algunos no piensen así, eso sucede.

A primera vista se percibe que, en ambas opiniones, lo que comentan los demás participantes en las redes es temido debido al miedo o al recelo de exponerse y de tornarse vulnerable ante los demás participantes (Rosa \& Santos, 2014b). Sin embargo, el entrevistado Rodrigo, aunque esté de acuerdo con el hecho de que las personas tienden a exponer apenas el lado considerado positivo de ellas mismas, destacó que concibe esa manera de exponerse como falsa:

Estoy de acuerdo. De hecho, hay un link que dice que nadie coloca en el Facebook que es molesto. Yo coloco que soy molesto. Pero la mayoría vende un pescado que nos es el suyo; una cosa que no es real, no es verdadera. Solo el lado positivo, lo que es interesante, lo que es atrayente. Una imagen que no es de ellas. Están siempre felices, sonriendo, siempre eso, siempre aquello. Entonces, yo estoy de acuerdo.

Aunque Rodrigo no se refiera a los considerados perfiles falsos (fakes), en los cuales es sabido que se utilizan datos que no son verídicos en relación con los dueños de esos perfiles (Mocellin, 2007), él argumenta que considera falsa esa exposición limitada apenas a los aspectos 
positivos. Con una opinión similar, la entrevistada Rafaela también se refirió a un ambiente donde "todos son felices":

Este...yo veo que existen muchas personas que solo postean cuando están bien, que solo postean fotos de viajes, que nunca postean cuando están tristes. Una vez una amiga me dijo, cuando entré en el Face: 'bienvenida al mundo en donde todos son felices.' Todo el mundo está siempre feliz. Una vez hasta comparti un post así: 'en Facebook, todo el mundo es activista politico, todo el mundo es siempre feliz, todo el mundo es siempre optimista, superado. Entonces, hallo que existe eso. Pero yo intento mostrar quien soy de verdad.

En esos relatos, los entrevistados afirman saber que las personas tienden a mostrar solamente el lado positivo. Rodrigo y Rafaela, particularmente, exponen aspectos considerados negativos. A pesar de que ambos consideren, de cierto modo, que se trata de una manera falsa de exponerse en la red por limitar la exposición sus aspectos negativos, ninguno de los entrevistados sostiene que haya construcción, recreación o idealización de identidades, pero sí una exposición de aspectos positivos. Por ello, con base en estas constataciones, se vuelve precaria una posible comparación entre la tendencia de exponer esos aspectos positivos y una posible simulación (Baudrillard, 1991), en la cual los usuarios estarían simulando ser lo que no son o, entonces, creando otra identidad, como ocurre en el caso de los perfiles falsos ( $f a k e$ ) (Mocellin, 2007). Por el contrario, tal como identificaron Back, Stopfer, Vazire, Gaddis, Schmukle, Egloff y Gosling (2010), a pesar de una exposición que prioriza aspectos positivos, estos tienden a presentar datos verídicos y que corresponden, aunque parcialmente, a las identidades de los participantes.

Los entrevistados Cristiane y Cláudio, por su parte, opinaron que concuerdan con la tesis de la estetización; sin embargo, explicitaron, respectivamente, que hay posteos en los cuales se exponen aspectos considerados negativos y que existe una forma de "psicología inversa": "De acuerdo. Eso en los posts personales, pero existen posteos compartidos de asuntos más pesados, causas sociales, pobreza y todo eso". 
Yo nunca voy a postear algo negativo en relación a mi persona, salvo si es con el objetivo de hacer aquella psicología inversa, o sea, colocar algo para que la gente me diga 'no, no eres asi'. Entonces, yo concuerdo plenamente.

Sobre la base de esos relatos, ratificamos que el fenómeno de la estetización del selfopera de forma tácita, envuelve los demás participantes $y$, en medio al denominado proceso de negociación de identidades, se desarrolla, principalmente, según las circunstancias y los intereses de los participantes. Por lo tanto, se evidencia que se trata de un proceso complejo cuyas motivaciones y posibles variaciones precisan ser mejor elucidadas.

\section{Discusión: entre el miedo de exponerse y el deseo de ser reconocido}

Durante las entrevistas, los participantes mencionaron reiteradas veces que los actos de postear, poner "me gusta", comentar, borrar o compartir lo que se publica son uno de los grandes atractivos de las redes sociales. De acuerdo con los entrevistados, posteriormente al acto de postear y de aguardar por los comentarios o por personas que le pongan "me gusta" al posteo, surgen los siguientes cuestionamientos: “¿Qué entenderán las personas sobre lo que posteé? ¿Qué pensarán de mí?”. De este modo, se evidencia que, de hecho, en las redes, lo que es posteado por un usuario es directamente asociado por los demás a su forma de pensar, de sentir, de comportarse y, consecuentemente, de ser (Rosa \& Santos, 2013).

Continuando por esa línea de raciocinio, percibimos, en las entrevistas, que los participantes buscan diferenciarse, ser reconocidos y hasta admirados por lo que se postea en la red, tal como reveló Rafaela en lo que concierne a la forma en que ella se siente después de obtener un retorno (feedback) considerado positivo acerca de sus posteos:

$Y$ me hace muy bien tener ese feedback de las personas; me afecta, seguro, a la larga, pues me hace percibir que yo soy importante, que yo puedo hacer la diferencia y acrecentar algo en la vida de las personas. 
Con ese comentario, podemos inferir que no solamente se teme lo que se postea en la red, pero que también se venera y se anhela a que haya comentarios positivos sobre lo que uno publica. Por ende, una de las motivaciones que influencia a las personas a postear en mayoritariamente aspectos considerados positivos es, por consiguiente, una supuesta búsqueda de reconocimiento y respeto una vez que, tal como mencionó la entrevistada Rafaela, por intermedio de las interacciones en las redes sociales, es posible asegurarse de su importancia en la vida de los demás, convirtiéndose en una persona significativa para ellos. En efecto, podemos señalar que la motivación procedente del miedo de exponerse y de volverse vulnerable ante los demás (Rosa \& Santos, 2014b) es contrapuesta por una búsqueda por ser importante, diferente y reconocido. Por lo tanto, existe una aparente contradicción que fomenta el fenómeno de la estetización del self: el miedo o recelo de exponer aspectos considerados despreciables o vulnerables y la búsqueda por ser diferente, importante o especial y ser reconocido como tal.

En semejante búsqueda, entendemos que ser considerado diferente, importante y hasta especial es una manera anhelada de ser reconocido por los demás. Por un lado, en lo que se refiere a la identidad de los participantes, afirmamos que el reconocimiento está basado en el sentido de que el individuo necesita de los otros para su existencia, o sea, se ve a sí mismo con los ojos de los otros y formula la imagen que tiene de sí mismo con base en aquella que se le es presentada por otras personas (Bourdieu, 1966). Por otro lado, en lo que concierne a ser diferente, especial o importante, inferimos que este sentido está directamente relacionado con la noción de respecto, siendo este derivado del prestigio y de la consideración que una persona posee por ocupar un determinado estatus en la jerarquía social o por la estima social procedente de los intercambios humanos fundamentados en los valores universales (Sennet, 2003/2004). De tal modo, dichas características, relacionadas con el reconocimiento y el respeto fueron evidenciadas también en el siguiente comentario de Miguel: 
A veces, me encuentro metido en Facebook mirando el feed y algunos perfiles, interesado en saber qué están haciendo las personas, con quienes andan, si están bonitas, si engordaron, si están con alguien, si están felices. Creo que eso se ha vuelto más constante con el uso del Face. Además de eso, busco esconder determinadas cosas en el Face para son ser tan común como algunas personas que lo tienen todo allá. Prefiero mantener un cierto suspense, mostrarme como diferente, especial. Qué sé yo... [risas]

Según Miguel, él procura saber cómo están las personas por las redes sociales, pero, a la vez, opta por mostrarse diferente y especial manteniendo cierta discreción. Mediante la comparación de las narrativas de los entrevistados y las perspectivas teóricas mencionadas, podemos reiterar que los sentidos subyacentes atribuidos por los entrevistados al fenómeno de la estetización del selfson: el miedo de tornarse vulnerable y el deseo por ser reconocido, diferente o importante. Volverse vulnerable, en este sentido, puede estar asociado a poseer características que remitan a los estigmas sociales (Goffman, 1978). La búsqueda por convertirse en diferente, reconocido o importante, por su vez, se asemeja a la exaltación de aspectos narcisistas que han sido detectados como una peculiaridad sobresaliente de los ambientes de redes sociales en internet (Wilson, Fornasier \& White, 2010). Sin embargo, yendo más allá de estas motivaciones contradictorias, corroboramos que los desdoblamientos del fenómeno de la estetización del self ocurren de manera dialéctica en las interacciones diarias entre los usuarios, tal como resaltó Verónica:

Bueno, por ejemplo, estoy triste. Voy y pongo una frase de ánimo. En estos sites que nos gustan, siempre aparecen las notificaciones sobre lo que le gusta a las demás personas. Luego, voy y, si encuentro algo interesante, posteo. [...] Hay veces en la cuales yo pienso en lo que estoy sintiendo, pero cuando encuentro algo divertido y sé que les va a gustar a las personas, voy y posteo [...] Cuando a los otros les gusta, es una sensación muy buena. Cuando no, pienso que lo que posteé no valió de nada. Me quedo con la expectativa del tipo vamos a ver a quien le va a gustar'. Ah! Y cuando comparte lo que posteé, 'yo me siento'. Me gusta. 
[¿Cómo se siente cuando comentan una foto tuya y cuando no la comentan?] Si el comentario es bueno, me gusta. Si el comentario es malo, no. Cuando no comentan nada, no me gusta y pienso asi: 'Ah! qué foto sin gracia'.

Verónica explicitó entre lo que se postea en fotos y los comentarios, lo que se comenta y lo que se piensa y se siente luego de estos actos. En sus palabras, ella dice que suele buscar frases de ánimo cuando está triste; cuando a las personas les gusta lo que ella postea, ella afirma sentir una “sensación muy buena". Del mismo modo, al postear una foto y esperar por sus respectivos comentarios, si nadie comenta, ella piensa "qué foto sin gracia”. A pesar de esa correlación establecida por ella, observase también una contradicción en lo que se refiere al sentido que tenía la imagen posteada por ella y el sentido que esta misma imagen adquirió después de no haber recibido ningún comentario. $\mathrm{O}$ sea, al principio, la imagen posteada había sido posteada por, supuestamente, haber sido considerada buena. No obstante, el sentido atribuido por ella a partir de la ocurrencia o no de comentarios, según la entrevistada, es capaz de transformar el sentido que originó el acto de postear y, por ende, la consideración que la misma foto recibirá por parte de ella. Así, evidenciase como la entrevistada relata su pensamiento que es al mismo tiempo coherente e incongruente luego de una interacción en la red, teniendo como efecto el surgimiento de nuevos sentidos atribuidos a la foto.

La narrativa de Verónica ratifica y ejemplifica lo que fue evidenciado a lo largo de las entrevistas: el fenómeno de la estetización del self transcurre por intermedio de las interacciones diarias y revela el proceso dialéctico e intersubjetivo que se establece en el ambiente de las redes sociales. Como resultado de este proceso, evidenciamos otros núcleos de sentido antagónicos relacionados al hecho de poder seleccionar los aspectos considerados positivos y, por lo tanto, controlar la imagen de sí mismo que cada usuario transmite en las redes y, al mismo tiempo, no poder actuar de esta manera, pues, en las interacciones, lo que se postea es comentado, recibe el "me gusta" o no, es criticado o no y es alabado o no. 


\section{Edición de la vida: entre la imagen transmitida y la realidad vivida}

La disposición de imágenes y de comentarios en el perfil de un usuario en la página inicial o en el "Feed de noticias" de una red social se configuran en un semblante capaz de aportar sentidos a lo que se desea transmitir y expresar. En la medida en que una imagen nos es atribuida, en que una connotación propia nos es dada, la podemos reposicionar, comentar, modificar o, estratégicamente, enfocarla de otra manera. Surge, entonces, la posibilidad de que esa misma imagen pueda denotar sentidos distintos para los que la ven (Barthes, 1986/2004). De este modo, reiteramos nuestra consideración de que el contexto, las circunstancias y la secuencia de posteos que componen la modalidad de estetización están íntimamente interrelacionados a lo que sucede tanto dentro como fuera de la redes, en el universo intersubjetivo y relacional de cada persona.

En esta perspectiva, percibimos que la composición interactiva de esta disposición de imágenes y de textos ocurre, por ejemplo, de la forma como explicita el entrevistado Rodrigo mediante la utilización del término documental: "Es así, si sucede algo, alguna cosa, tú haces como un documental allí. Se expresa o se coloca alguna foto, alguna cosa". Documentar, en este caso, se refiere a registrar, en las redes, lo acontecido. Registrar, por tanto, implica la captación en foto, en video o en comentario de los datos de la realidad que podrán ser utilizados de la manera que quieran los usuarios. Asimismo, la posibilidad de registrar, modificar, agregar, ocultar o borrar lo que será documentado en las redes se transforma en una particularidad inherente al fenómeno de la estetización del self en este universo de la interactividad entre dentro y fuera de las redes. También se evidencia, de este modo, la influencia de los recursos y dispositivos presentes en las redes y en los celulares que, de alguna manera, fomentan este registro estético y propician interacciones con base en lo que se publica.

Un ejemplo nítido de esta influencia es la red social Instagram, cuyo servicio se basa en la posibilidad de compartir fotos e imágenes y que tiene como misión institucional a la capacidad de reportar y de 
transmitir lo que ocurre en la vida de cada persona a través de fotos e imágenes, tal como informa en su página principal: "Instagram es una manera rápida, bonita y divertida de compartir tu vida con amigos y familia"' Al "compartir tu vida", según lo que propone este sitio de red social, el usuario estaría en contacto con seres queridos y demostraría lo que está ocurriendo en su vida por medio de lo que se comparte. Sin embargo, lo que sobreviene en este esplendoroso escenario de redes, frecuentemente, no demuestra ni tampoco expresa plenamente lo que ocurre en la vida de las personas, tal como resalta el entrevistado Claudio:

Por ejemplo, vos posteás las fotos de un viaje que hiciste, que pasaste veinte años juntando la plata para viajar. $Y$ las personas te ponen comentarios del tipo 'Qué lindo!', 'Me encantó!' Solo que, por detrás de aquellas fotos, las personas no tienen ninguna noción de cuanto te constó, del tiempo que pasaste juntando el dinero. Es prácticamente lo que dijiste de la 'estetización', porque las personas ven solamente lo que está allá. Del trabajo que tuviste para llegar a eso, nadie tiene noción.

A primera vista, el hecho de que las personas vean solamente "lo que está allá", como resalta Claudio, permítenos pensar que el fenómeno de la estetización del self posibilita enfocar específicamente lo que será transmitido y pautar, de cierta manera, los comentarios que serán efectuados en base a eso. En otras palabras, es posible transmitir la imagen que se desea sobre la vida personal uno y, consecuentemente, sobre su identidad. En casos extremos, por el exceso de estetización, podemos vislumbrar la posibilidad de que eso venga a sobreponerse a la vida misma de uno y originar una ilusión entre los participantes (Baudrillard, 1999). No obstante, fuera de los casos extremos, podemos pensar que la posibilidad de una supuesta ilusión es inocua por el simples hecho de que los propios participantes saben, de forma tacita, que aquello que se expone no es la totalidad de sus vidas ni tampoco de sus identidades, tal como reveló Roberto, entrevistado por Rosa (2012, p. 76):

5 Traducción libre: "Instagram is a fast, beautiful and fun way to share your life with friends and Family.” (Instagram, 2014). 
"Cuando creas tu perfil, no es que creas una nueva identidad; creas una identidad que no es tu totalidad".

Ante estas evidencias, las tesis de ocurre la construcción de una nueva identidad (Zhao, Grasmuck \& Martin, 2008; Mehdizadeh, 2010; Fonseca, 2010) y la de que hay una recreación de identidades en las redes sociales (Yurchisin, Watchravesringkan \& McCabe, 2005) se vuelven frágiles. Los propios participantes alegan que exponen apenas partes de sus vidas y, por consiguiente, de sus identidades. Esas "partes", tal como mencionó Roberto, no son concebidas como la totalidad de sus identidades porque no son "tu totalidad". Asimismo, partiendo del presupuesto de que sería inverosímil que una exposición dentro o fuera de la red pueda abarcar la totalidad de nuestra identidad, reiteramos que existe una selección de lo que se convertirá en público. Sin embargo, la tesis que defiende que hay un gerenciamiento de las identidades de los participantes (Dimicco \& Millen, 2007; Strano, 2008; Magalhães \& Paiva, 2009) tampouco se muestra eficaz si consideramos la influencia ajena y la interacción con los demás usuarios dentro y fuera de las redes como un factor que incide directamente en la selección de lo que será publicado. Tal como resaltaron los entrevistados, cabe reiterar que los comentarios sobre los posteos son, al mismo tiempo, temidos (por el miedo de exponerse y tornarse vulnerable ante los demás usuarios) y anhelados (por una búsqueda por ser diferente, importante o especial). Por tanto, la forma en que cada uno se expone o no en la red guarda una relación directa con lo que ocurre no solamente adentro de la propia red, pero también fuera de este ambiente, en la vida personal de cada usuario.

En lo que concierne a la influencia de los comentarios, todos los entrevistados alegaron saber que hay determinados comentarios que traspasan lo que se postea en la red y operan en la continuidad de las relaciones entre dentro y fuera de las redes, o sea, en la llamada vida presencial. Esto es, todos los entrevistados afirman saber que se comenta sobre lo que ellos hacen dentro del ambiente de las redes y fuera y viceversa. Por ello, enfatizamos que las interacciones entre los participantes influencian la forma en que se da el fenómeno de la estetización del self 
$y$, por consiguiente, los comentarios dentro y fuera de las redes pueden acarrear transformaciones en la manera en que cada uno se presenta en el ambiente online, como bien especificó la entrevistada Magda:

Me sentía bien. Últimamente, yo me siento más desconfiada porque hubo algunos comentarios en una foto que no me gustaron. Cuando pasó eso, yo comenté y la persona comentó de vuelta y comenzó medio que una pelea. La persona se ofendió y yo me quedé muy triste con el Face. Hasta me dieron ganas de excluirlo. No lo hice, pero saqué muchas cosas como, por ejemplo, las fotos.

En este ejemplo de experiencia personal, luego del desarrollo de las interacciones, Magda pasó a considerar a los comentarios como fuente de desconfianza. Y eso resultó en un cambio en la forma en que ella se presenta en las redes y ella empezó a optar por no postear más fotos en su perfil para no sujetarse más a comentarios ajenos y posibles chismes. Así, si consideramos a los chismes no solamente como una visa de transmisión de hechos y versiones sino también como una vía que permite interpretar y atribuir intenciones a acciones y a los dichos (Gaiarsa, 1978), podemos afianzar que el fenómeno de la estetización del self es realizado para ofrecer determinados datos con la finalidad de que los participantes vean y comentes y, consecuentemente, puedan interpretar y atribuir intenciones a las acciones y dichos. En el caso de Magda, ella prefirió no ofrecer datos en fotos, para que determinados comentarios no tengan lugar nuevamente.

No obstante esa constatación, podemos vislumbrar también la posibilidad de que otros usuarios puedan actuar de forma opuesta, o sea, ofreciendo datos para que, en las interacciones, los demás participantes interpreten y atribuyan intenciones a lo que se trasmite en las redes. En una perspectiva similar, al observar la propulsión de la llamada sociedad del espectáculo en los dispositivos de la internet, Sibilia (2008) demostró como la vida íntima y el culto al ego pueden transformarse en objeto de consumo, induciendo algunas personas a difundir aspectos personales en las redes en la búsqueda por audiencia. En este sentido, más allá de la posibilidad de que no todos actúen de esta manera, como 
revelaron los entrevistados, esa es una característica también relevante de esta modalidad de interacción en las redes sociales.

En el plan simbólico, podemos interpretar que, de modo general, las representaciones efectuadas en las redes se convierten en un conjunto de medios y de procesos a través de los cuales realidades imaginarias pueden encarnarse en materiales y prácticas, adjudicándoles existencia social manifiesta y visible (Godelier, 2014). Así, además de ofrecer un soporte audiovisual para que se puede estar y interactuar en las redes, el fenómeno de la estetización del self, en esta perspectiva, vincula a los participantes entre sí y engendra un proceso dialéctico de producción subjetiva que puede venir a ratificar, rectificar o simplemente a propagar lo que se publica en las redes. De este modo, los rasgos y características de las identidades de los participantes que son negociados en las redes pueden ser experimentados de manera peculiar por los usuarios según las circunstancias, los intereses contrapuestos y las personas con las cuales ellos interactúan.

En conclusión, teniendo como presupuesto que la identidad está compuesta por la articulación entre igualdad y diferencial (Lima, 2009/2010), ratificamos que el fenómeno de la estetización del self en las redes sociales de internet ocurre de forma dialéctica en el cotidiano de millones de personas y puede generar sentidos para la composición identitaria de esas personas o para el sentido de sí mismas que ellas tienen (Turkle, 1994; Rosa, 2014). En este contexto, más allá de la posibilidad de exponer rasgos y características consideradas positivas de sus identidades, las personas están sujetas a los contrastes y contradicciones entre lo que se publica en las redes y lo que sucede fuera de estos ambientes, entre lo que se comenta dentro y fuera de las redes, tal como relata Roseane: "En el Face es una cosa y aquí es otra. Tipo, en el Face es súper puta y aquí en la iglesia es una santa. Ni parece la misma”.

Ante esas evidencias, aseveramos que ese fenómeno de la estetización del self en las redes se constituye en un receptáculo o en imagen contenedora que puede traer, consigo, ciertos elementos no dichos, no percibidos o inconscientes de un supuesto telespectador emancipado (Rancière, 2012). Esos elementos, cuando estetizados y en contacto 
con la interferencia causada por los demás usuarios pueden traer, a la baila, otros aspectos ocultados, desapercibidos y hasta disimulados. De este modo, corroboramos que la selección de lo que será expuesto en la red varía de acuerdo con los intereses, con las circunstancias y con las personas con las cuales los usuarios interactúan, y que el efecto de esa trama no puede ser considerado como la construcción de una nueva identidad o como mero gerenciamiento de las identidades de los participantes. Puede, sin embargo, ser entendida como la estetización de esa imagen que se pretende transmitir y experimentar y que, frecuentemente, expresa contradicciones (De Certeau, 1988) entre la realidad circundante, la composición identitaria de cada persona y la imagen que uno posee de sí mismo.

En síntesis, si consideramos que, por un lado, la autopoieses del cuerpo social tiene tanta importancia como el maquinaria interno, por otro lado, que las apariencias operan como pivote alrededor del cual se va a ordenar en círculos concéntricos toda la vida social (Maffesoli, 1996/2010), podemos concluir afirmando que la estetización del self es un fenómeno propulsor de la producción subjetiva en la actualidad.

\section{Consideraciones finales}

Las repercusiones del fenómeno de la estetización del self son la expresión intensa de las contradicciones del ser humano por medio de los recursos y dispositivos audiovisuales de las redes sociales. Nuestros anhelos, carencias y peculiaridades están se tornando cada vez más visibles en esta mescla entre imagen y discurso, entre dentro y fuera del mundo online, entre figura y fondo. Este fenómeno tiende a nos transformar no solamente en sujetos más visibles e interactivos, pero también más capaces de evidenciar a sí mismo y a los otros en medio a esta trama intersubjetiva de las redes. Y este es un fenómeno que precisa recibir más atención en los medios académicos.

Las posibles consecuencias de este fenómeno en la sociedad y en el psiquismo de las personas necesitan ser mejor estudiadas. Por un lado, 
la influencia de los ideales propagados por el mercado genera una tendencia al consumo hedonista y al culto narcisista que han sido evidenciados en investigaciones como consecuencias funestas del fenómeno de la estetización del self. Por otro lado, el incremento de las aptitudes interaccionares comunicativas, la ampliación del nicho relacional y el acceso al conocimiento y a otras culturas también han sido destaques en las investigaciones. Otra vía para exploración de este amplio campo de las identidades en las redes es la de la relación entre el yo y el otro o entre identidad y alteridad que, bajo el fenómeno de la estetización del self, establece un puente que puede conducirnos hacia otros caminos, entre los cuales, este que aquí abordamos.

\section{Referencias}

Abep - Associação Brasileira de Empresas de Pesquisa (2012) - Dados com base no levantamento socioeconômico 2010 - IBOPE. Recuperado el 14 mayo de 2015, de www.abep.org - abep@ abep.org

Back, M. D., Stopfer, J. M., Vazire, S., Gaddis, S., Schmukle, S. C., Egloff, B. \& Gosling, S. D. (2010). Facebook profiles reflect actual personality, not self-idealization. Psychological Science, 3(21), 372-374. http://dx.doi.org/10.1177/0956797609360756

Barthes, R. (2004). O óbvio e o obtuso: ensaios críticos III. Rio de Janeiro:

Nova Fronteira. (Originalmente publicado en 1986).

DaMatta, R. (1986). O que faz o brasil, Brasil? Rio de Janeiro: Roco.

Baudrillard, J. (1991). Simulacros e simulaçóes. Lisboa: Relógio D'água. Baudrillard, J. (1999) Tela total: mito-ironias da era do virtual e da imagem. 2a. ed. Porto Alegre: Sulina.

Bourdieu, P. (1966). The sentiment of honour in kabyle society. (P. Sherrard, Trad.). En J. G. Péristiany (Org.), Honour and shame: the values of mediterranean society (pp. 192-141) Chicago: University of Chicago Press. 
Bourdieu, P. (1977). Outline of a theory of practice. (R. Nice, Trad.). Cambridge: Cambridge University Press. http://dx.doi. org/10.1017/CBO9780511812507

De Certeau, M. (1988). The practice of everyday life. California: University of California Press.

Dimicco, J. M. \& Millen, D. R. (2007). Identity management: multiple presentations of self in Facebook. IBM T. J. Watson Research, Cambridge-MA, 2007. Recuperado el 14 de mayo de 2015, de http://citeseerx.ist.psu.edu/viewdoc/download?doi=10.1.1.127.

Fonseca, C. A. M. (2010). Cartografias do self no Facebook. Dissertação (Maestría en Sociologia). Universidade de Coimbra, Coimbra.

Gaiarsa, J. A. (1978). Tratado geral sobre a fofoca: uma análise da desconfiança humana. São Paulo: Sumus.

Geertz, C. (2008). A interpretação das culturas. Rio de Janeiro: LTC. (Original publicado em 1988).

Godelier, M. (2014). Em el fundamento de las sociedades humanas: qué nos enseña la antropologia. Buenos Aires: Amorrortu.

Goffman, E. (2009). A representação do eu na vida cotidiana. 17. ed. (M. C. S. Raposo, Trad.). Petrópolis: Vozes. (Originalmente publicado em 1975).

Goffman, E. (1978). Estigma: notas sobre a manipulação da identidade deteriorada. 2. ed. (M. B. de M. L. Nunes, Trad.). Rio de Janeiro: Zahar. Groeben, N. (1990). Subjective theories and the explanation of human action. En G.R. Semin \& K.J. Gergen (Orgs.), Everyday understanding social and scientific implications (pp. 19-44). London: Sage.

Instagram (2014). Recuperado en 14 maio, de 2015, de http:// instagram.com.

Lemos, A. \& Lévy, P. (2010). O futuro da internet: em direção a uma ciberdemocracia planetária. São Paulo: Paulus. (Coleção Comunicação).

Leite, D. M. (1967). Questóes básicas para o estudo da personalidade. En D. M. Leite, Personalidade (pp. 3-24). São Paulo: Companhia Editora Nacional. 
Lima, A. F. (2010). Metamorfose, anamorfose e reconhecimento perverso: a identidade na perspectiva da psicologia social crítica. São Paulo: FAPESP/EDUC. (Originalmente publicado em 2009).

Lipovetsky, G. \& Serroy, J. (2009). A tela global: midias culturais e cinema na era hipermoderna. (P. Neves, Trad.). Porto Alegre: Sulina. (Originalmente publicado em 2007).

Maffesoli, M. (2010). No fundo das aparências. (B. H. G., Trad). 4a ed. Petrópolis, RJ: Vozes. (Originalmente publicado em 1996).

Magalhães, M. \& Paiva, C. C. (2009). Estilos de identidade nas redes sociais de relacionamento. Cultura Midiática, 2(2) 1-9.

Mehdizadeh, S. (2010) Self-presentation 2.0: narcisism and self-esteem on Facebook. (2010). Cyberpsychology, Behavior, and SocialNetworking, 3(4), 357-364. http://dx.doi.org/10.1089/cyber.2009.0257

Mocellin, A. (2007). Internet e identidade: um estudo sobre o website Orkut. Tese, 3(2), 100-121.

Rancière, J. (2012). O espectador emancipado. São Paulo: Martins Fontes. Rosa, G. A. M. (2012). Facebook: negociação de identidades, medo de se expor e subjetividade. Dissertação de Mestrado, Programa de Psicologia da Universidade Católica de Brasília.

Rosa, G. A. M. (2014). Construção e negociação de identidades. Curitiba: Juruá.

Rosa, G. A. M. \& Santos, B. R. (2013). Facebook e as nossas identidades virtuais. Brasília: Thesaurus.

Rosa, G. A. M. \& Santos, B. R. (2014a). Who am I on Facebook? Usage and motivation through user eyes. Psychology Research, 14(1), 60-73.

Rosa, G. A. M. \& Santos, B. R. (2014b). Facebook: negociação de identidades e o medo da violência. Arquivos Brasileiros de Psicologia, 66(1), 18-32.

Sennet, R. (2004). Respeito: a formação do caráter em um mundo desigual. (R. Vinagre, Trad.). Rio de Janeiro: Record. (Originalmente publicado em 2003).

Siibak, A. (2007). Reflections of RL in the virtual world. Cyberpsychology: Journal of Psychosocial Research on Cyberspace, 1(1). Recuperado 
el 14 mayo de 2015, de http://cyberpsychology.eu/view. php?cisloclanku=2007072301.

Sibilia, P. (2008). O show do eu: a intimidade como espetáculo. Rio de Janeiro: Nova Fronteira. (Original publicado en 2001).

Strano, M. M. (2008). User descriptions and interpretations of selfpresentation through Facebook profile images. Cyberpsychology: journal of Psychosocial Research on Cyberspace, 2(2), article 1. Recuperado el 14 mayo de 2015, de http://cyberpsychology.eu/ view.php?cisloclanku=2008110402\&article $=1$

Teixeira, J. S. (1992). Pessoa. Verbete da Logos: Enciclopédia Luso-Brasileira de Filosofia (pp. 95-120). Lisboa/São Paulo: Editorial Verbo.

Turkle, S. (1997). Life on the screen: identity in the age of the internet. New York: Simon \& Schuster.

Velho, G. (2008). Goffman, mal entendidos e riscos internacionais. Revista Brasileira de Ciências Sociais, 23(68), 145-148. http:// dx.doi.org/10.1590/S0102-69092008000300012

Wilson, K., Fornasier, E. \&White, K. M. (2010). Psychological predictors of young adult's: use of social network sites. Cyberpsychology, Behavior and Social Networking, 13(2), 173-177. http://dx.doi. org/10.1089/cyber.2009.0094

Yurchisin, J., Watchravesringkan, K. \& McCabe, D. B. (2005). An exploration of identity re-creation in the context of internet dating. Social Behavior and Personality, 33, 735-750. http:// dx.doi.org/10.2224/sbp.2005.33.8.735

Zarghooni, S. (2007). A study of self-presentation in light of Facebook. Institute of Psychology, University of Oslo. Disponível em http:// zarghooni.files.wordpress.com/2011/09/zarghooni-2007selfpresentation_on_facebook.pdf. Acesso en agosto de 2014.

Zhao, S., Grasmuck, S. \& Martin, J. (2008). Identity construction on Facebook: digital empowerment in anchored relationships. Computer in Human Behavior, 24(5), 1816-1836. http://dx.doi. org/10.1016/j.chb.2008.02.012

Recibido: 20 de mayo, 2015 Aceptado: 13 de abril, 2016 